\title{
Emotional intelligence as an indicator of satisfaction with life of patients with psoriasis
}

\author{
Małgorzata A. Basińska, Marta Drozdowska
}

Department of Psychopathology and Clinical Diagnosis, Institute of Psychology, Kazimierz Wielki University, Bydgoszcz, Poland Head of Department: Małgorzata A. Basińska PhD, Prof. KWU

Postep Derm Alergol 2013; XXX, 6: 365-372

DOI: 10.5114/pdia.2013.39435

\begin{abstract}
Introduction: Research reports confirm the existence of a relation between emotional intelligence and various aspects of human functioning. It protects psychical and physical health of an individual, helps to adapt to new conditions and, consequently, contributes to the increase in life quality expressed in satisfaction with life. Psoriasis, a chronic skin disease, may negatively influence the psychical state of a patient and his or her social functioning, which leads to the decrease in satisfaction with life.

Aim: This research aimed at determining the relation between emotional intelligence and satisfaction with life in a group of patients with psoriasis.

Material and methods: The research group consisted of 81 people with psoriasis ( 40 men and 41 women) with the average age of $41.22(S D=14.18)$. The research tools used included the Emotional Intelligence Questionnaire INTE, Satisfaction With Life Scale (SWLS), personal questionnaire and PASI scale.

Results: There is a positive correlation between emotional intelligence and satisfaction with life in the group of patients with psoriasis. Especially factor I - using emotions in thinking and operating - positively correlates with satisfaction with life.

Conclusions: Emotional intelligence together with the percentage of body area taken by pathological changes are the indicators of satisfaction with life in patients with psoriasis.

Key words: emotional intelligence, satisfaction with life, psoriasis, psycho-dermatology, psychosomatics.
\end{abstract}

\section{Introduction}

Psoriasis as an example of a chronic disease

Psoriasis is one of the most frequent, chronic and recurrent skin diseases. In Poland the incidence of psoriasis is estimated at $2 \%$ of the population [1]. The disease occurs both in men and women [2, 3].

The disease manifestation includes numerous pathogenic changes occurring in human skin [4]. However, the basic phenomenon found in psoriasis is the excessive division of keratinocytes and their faster than usual and abnormal cycle of differentiation [1]. It is the result of immune system disorders $[4,5]$. Genetic factors play a major role in psoriasis pathogenesis [1], and upper respiratory tract infections are one of the factors that trigger the disease. Some medicine such as lithium, non-steroidal anti-inflammatory drugs and steroids may contribute to the occurrence of psoriasis [3, 4]. Moreover, psychological stress is a factor that causes the occurrence of psoriasis changes as well as subsequent attacks [4]. The relation between psoriasis processes and stress is frequently mentioned in the literature $[4,6]$. The development of that cutaneous condition may be modified by stress, emotional conflicts and also a tendency to suppress one's feelings $[7,8]$. It is thought that the activity of stress is bi-directional, i.e. stress strongly influences the appearance of psoriasis changes, but the appearance of those changes and the life with psoriasis is also a cause of stress [9-12].

It was noticed that patients with psoriasis may suffer from an emotion regulation disorder called alexithymia $[13,14]$. The disorder involves disability to understand or identify emotions and to name and express them. People with psoriasis, who are diagnosed as alexithymics, had difficulty in revising their life situation related to the disease and adapting to the changes resulting from that chronic disease [15].

Psoriasis influences the quality of the ill in a significantly substantial way as it is a chronic disease and also by its nature, i.e. the occurrence of changes in uncovered

Address for correspondence: Małgorzata A. Basińska PhD, Prof. KWU, Department of Psychopathology and Clinical Diagnosis, Institute of Psychology, Kazimierz Wielki University, 1 Staffa St, 85-867 Bydgoszcz, Poland, e-mail: mbasinska@ukw.edu.pl Received: 25.12.2012, accepted: 7.11.2013. 
body parts [16]. Furthermore, psoriasis strongly affects family and personal life of the patients. They shun social activities and attending public places, avoid sunbathing, swimming, visiting hairdressers and using public transport [17].

\section{Satisfaction with life}

The subjective welfare of a person is determined by two closely related components: the emotional and cognitive ones. The latter, described as satisfaction with life (SWL), concerns the way an individual evaluates the quality of his or her life basing on his/her own, unique set of criteria. A global evaluation of one's life is crucial here, not satisfaction with specific achievements or life areas. Satisfaction with life constitutes the result of a long-term reflection as opposed to not a short-term one [18]. It is the evaluation of life as a whole and it is relatively permanent as such.

The research shows that satisfaction with life is determined by personal qualities, mainly personality traits and the acceptance of oneself to a large extent [19]. The connection to emotionality, including one's moods, also affects the global satisfaction with life in a significant way. Depression, embarrassment and negative affection are predictors of low satisfaction with life, whereas vigour - of a higher one [20].

Objective factors such as properties of wealth or culture the man lives in also turned out to significantly correlate with satisfaction with life [19-22]. Direct factors such as the current situational context influence the responses of the researched as well [18]. Satisfaction with life depends, therefore, on long-term (e.g. personal traits), medium-term (e.g. life events and cognitive schemas) and short-term components (e.g. current mood) [18].

Age and gender generally show a little or no relation to satisfaction with life [18]. Women and young people are slightly more satisfied with life [22].

Satisfaction with life may be treated as a manifestation of psychological adaptation and an indicator of life quality. The relation between satisfaction with life and a disease, including a chronic disease, has been investigated to a small degree. In a group of patients with asthma, the disease lowered satisfaction with life in general, however, it was strongly correlated with a high level of neuroticism of those patients [23]. Polish research suggests that menopausal women $(M=18.42)$ and men after myocardial infarction $(M=18.78)$ have the lowest satisfaction with life, whereas diabetics $(M=20.34)$ and pregnant women with complications ( $M$ $=21.34$ ) the highest [24]. The research into people with endocrinological disorders revealed that the highest level of satisfaction is found in patients with Graves-Basedow disease $(M=21.46)$, while the lowest in those with type 1 diabetes $(M=18.31)$ and Hashimoto's disease $(M=18.76)$. In the researched groups of patients, the chronic disease was not related to lowered SWL; its level was similar to that of the group of healthy people $(M=19.85)$ [25].

Not every chronic disease must result in lowered satisfaction with life. When it results in activating personal resources, which allow people to realize goals and satisfy important needs, then the situation is accepted and as a consequence SWL increases [26].

\section{Emotional intelligence as a personal resource of patients}

The development of psychoneuroimmunology and psychology of health as well as protests against the pathogenic approach of classical psychosomatics led to the intensification of research aiming at identification and determination of personality elements that play a modifying role in relation to risk factors and help to survive the disease and deal with it and its consequences.

Those factors are called personal resources as opposed to deficits that weaken reaction to stress and worsen the effectiveness of dealing with it [27]. In psychology of health they are also referred to as health potentials, while in psychology of stress as resistance qualities [28, 29].

The resources are defined in a number of ways, however, in a nutshell they may be described as such elements that protect the individual, may be used to satisfy one's needs, aspirations and goals, and prevent negative effects of stress as well as help to deal with difficult situations [30, 31]. Emotional intelligence (EI) is one of personal resources and therefore it helps among other things to accept a disease [29, 32, 33].

The term 'emotional intelligence' was introduced in 1990 by American psychologists Peter Salovey and John Mayer [34]. According to them, 'emotional intelligence' includes the capability of correct perception, evaluation and expression of emotions, the ability to access emotions and to generate them in the moments when they may enhance thinking, ability to understand emotions and the understanding of emotional knowledge, and ability to regulate emotions so that they support emotional and intellectual development' [35].

Such a definition of El indicates the possibility to develop and shape it in the course of activity, especially social activity, as it assumes that it is not innate. As a result, its development continues throughout the entire life of a person e.g. by gaining new experiences [36]. Interpersonal contacts allow one to learn to recognize, understand, control and predict both other people's and one's own emotions [37]. The importance of El has not been fully understood so far. However, there is a number of arguments supporting the idea that it significantly influences the effectiveness of a person dealing with numerous life situations [34]. It is difficult to determine precisely how many differences between various people that emerge in a lifetime may be explained by different levels of El [38]. Although currently there are numerous 
reports [32, 39] confirming the relation between El and various aspects of human functioning, its regulatory role has not been sufficiently understood.

Researchers asked themselves what aspect of emotional competencies protects people from stress, anxiety or depression, and, at the same time, helps to sustain a positive psychical state [40]. The experience of chronic disease always involves negative emotions that are connected with worse adaptation and an increase in stress. The evaluation of the disease and the emotional response to it influence all the spheres of a person's functioning. Emotional intelligence, and in particular one of its factors - using emotions in thinking and acting facilitate the disease acceptance by patients with psoriasis [29]. That is why determining the role of $\mathrm{El}$ is so important in a more global aspect such as satisfaction with life.

Since El shows a positive relation to adaptive strategies of dealing with difficulties and negative to non-adaptive ones [41], its positive relation to satisfaction with life may also be expected. All the more so because numerous research results indicate its relation to health [42]. Good regulation of emotions is a factor that increases the overall welfare of an individual [43].

\section{Aim}

The aim of the research was to determine the relation between the personal resource, that is El, and satisfaction with life in a group of patients with psoriasis. Therefore, it was assumed that people with a higher El would display higher satisfaction with life. Moreover, El was assumed to be a predictor of SWL.

Furthermore, it was checked whether those relations change when the differences in the health state of the researched people and demographic variables - age and sex-are taken into account.

\section{Material and methods}

Emotional Intelligence Questionnaire INTE by Schutte et al. was used to assess EI [34]. Both the original and Polish versions of the INTE Questionnaire are characterized by high internal consistency (Cronbach's $\alpha$ equals 0.87-0.90 and 0.83-0.87, respectively). The INTE Questionnaire also turned out to be a valid method [34].

The Satisfaction with Life Scale (SWLS) is designed to examine adults. The coefficient of reliability Cronbach's $\alpha$ is satisfactory and equals 0.81 . The validity of the tool was also confirmed [24].

The personal questionnaire is a tool used to collect and systematise basic data of the ill people taking part in the research and their health state.

Psoriasis Area and Severity Index (PASI) was originally designed by Torsten Frederiksson and UIf Pettersson [4]. It evaluates the severity of three skin symptoms: erythe- ma, infiltration and exfoliation. The area of body with pathological changes is also evaluated with that scale. The severity evaluation is performed separately for the head, trunk, upper limbs and lower limbs. The percentage of pathologically changed area is determined for each of those body parts [4].

For the needs of the research, the overall result of PASI was calculated and each participant could score between 0 and 48 points. Points for the percentage of pathologically changed skin area of particular parts of the body were calculated separately and participants could score between 0 and 24 points.

The research group was composed of people suffering from psoriasis diagnosed by a doctor specialising in dermatology. Psoriasis was the primary disease. The patients agreed to take part in the research. The research started after obtaining consent of the Committee of Bioethics and the Head of the Department.

Ninety-three patients were examined, however, 81 examinations were classified to the analysis as the remaining ones were incomplete. Forty-one women (51\%) and 40 men (49\%) were examined. The average age of the participants was 41 (SD =14.18), however, it ranged from 18 to 70 years. The education range was also large. As far as marital status is concerned, married people predominated and as regards the state of health, the majority of participants did not mention any complications or coexisting diseases.

The average length of disease was 18.42 years (SD = 12.97 ) with the range from several months to 52 years. The participants were hospitalized 4.43 times on average $(S D=9.11)$, ranging from 0 to 60 times.

In the group of examined patients with psoriasis, the average symptom severity measured with PASI was 15.77 (SD = 9.06; with the range from 2 to 46 points) and indicated a moderate degree of psoriasis severity. The score for the average body area with psoriasis changes was 9.84 (SD = 5.86; with the range from 0 to 24 ).

\section{Results}

In the examined group of people with psoriasis, there was a statistically significant correlation between El and satisfaction with life and between one of El factors - using emotions in thinking and acting - and satisfaction with life. The second of El factors - ability to recognise emotions - turned out not to be related to SWL in a statistically significant way (Table 1). The better the people were able to use emotions in thinking and acting, the more satisfied they were with their lives. Emotional intelligence in general correlated positively with satisfaction with life. However, such relations occurred only in the group of women and the elderly. They were not observed in the group of men and young people at all (Table 1). 
When analysing the relation between EI and satisfaction with life and taking the age of participants into account, it may be found that the relation is of different quality in the groups of younger and older patients. In the younger group, no statistically significant relation was found, whereas in the older group, the global El score and the factor of using emotions in thinking and acting correlated with satisfaction with life. Factor II ability to recognise emotions - did not reveal a statistically significant relation to SWL.

The results obtained were confirmed through multiple regression analysis. Emotional intelligence globally explained the variability in satisfaction with life in about $11 \%$ (correct. $R^{2}=0.113 ; F(1.79)=11.202 ; p<0.001$ ) in the examined group of patients. However, when El was divided into factors, the predictive characteristics of factor I (using emotions in thinking and acting), which explained the variability in about 9\% (correct. $R^{2}=0.099$; $p=0.006$ and $\beta=0.318 ; p=0.004$ ), was confirmed. Factor II (ability to recognise emotions) did not play a predictive role for satisfaction with life.

\section{Relation between El and its components and satisfaction with life taking the state of health into account}

In the examined group of people with psoriasis when taking psoriasis severity and the percentage of body area changed, there were statistically significant relations between $\mathrm{El}$ and its factors and satisfaction with life (Table 2). In the case of greater severity of psoriasis the relation between EI as a whole and SWL was significant, whereas in the case of smaller severity, only factor I - using emotions in thinking and acting - correlated significantly with SWL. If the percentage of body area changed by the disease was taken into account, both the whole construct and the two factors independently revealed a statistically significant correlation with SWL. With a smaller percentage of the area changed, neither El nor any of its factors independently revealed a statistically significant relation to SWL.

A statistically significant relation between SWL and El $(r=0.369 ; p=0.019)$ and its factor I - using emotions in thinking and acting $(r=0.443 ; p=0.004)$ was also

Table 1. $R$-Pearson correlation between emotional intelligence and its components and satisfaction with life in the whole group, taking sex and age into account

\begin{tabular}{lccccc}
\hline \multicolumn{1}{c}{ Emotional intelligence } & All & Women & Men & $\begin{array}{c}\text { Young } \\
(n=41)\end{array}$ & $\begin{array}{c}\text { Old } \\
(n=40)\end{array}$ \\
\hline \multirow{2}{*}{ INTE raw score } & 0.352 & 0.434 & 0.258 & 0.285 & 0.434 \\
\cline { 2 - 6 } & $p=0.001$ & $p=0.005$ & $p=0.107$ & $p=0.071$ & $p=0.005$ \\
\hline $\begin{array}{l}\text { INTE factor I - the use of emotions } \\
\text { in thought and action }\end{array}$ & 0.334 & 0.435 & 0.216 & 0.301 & 0.383 \\
\cline { 2 - 5 } $\begin{array}{l}\text { INTE factor II - emotion } \\
\text { recognition ability }\end{array}$ & $p=0.002$ & $p=0.005$ & $p=0.182$ & $p=0.056$ & $p=0.015$ \\
\cline { 2 - 5 } & $p=0.172$ & $p=0.217$ & $p=0.540$ & $p=0.129$ & $p=0.025$ \\
\hline
\end{tabular}

Table 2. $R$-Pearson correlation between emotional intelligence and its components and SWL, taking psoriasis severity and percentage of body area changed into account

\begin{tabular}{|c|c|c|c|c|}
\hline Emotional intelligence & $\begin{array}{l}\text { High severity of } \\
\text { psoriasis }(n=37)\end{array}$ & $\begin{array}{l}\text { Low severity of } \\
\text { psoriasis }(n=41)\end{array}$ & $\begin{array}{l}\text { Higher } \% \\
\text { of body area } \\
(n=38)\end{array}$ & $\begin{array}{l}\text { Lower } \% \\
\text { of body area } \\
(n=60)\end{array}$ \\
\hline \multirow{2}{*}{ INTE raw score } & 0.453 & 0.221 & 0.654 & 0.091 \\
\hline & $p=0.005$ & $p=0.165$ & $p<0.001$ & $p=0.594$ \\
\hline \multirow{2}{*}{$\begin{array}{l}\text { INTE factor I - the use of emotions } \\
\text { in thought and action }\end{array}$} & 0.285 & 0.372 & 0.614 & 0.058 \\
\hline & $p=0.087$ & $p=0.017$ & $p<0.001$ & $p=0.733$ \\
\hline \multirow{2}{*}{$\begin{array}{l}\text { INTE factor II - emotion recogni- } \\
\text { tion ability }\end{array}$} & 0.202 & 0.079 & 0.329 & -0.007 \\
\hline & $p=0.230$ & $p=0.624$ & $p=0.044$ & $p=0.965$ \\
\hline
\end{tabular}


observed when taking the disease length into account. In participants being ill for a longer time there were no statistically significant correlations between El, its factors and satisfaction with life found, while in the sub-group with a shorter disease history, such correlations were found.

\section{Prediction of satisfaction with life}

In the first stage of analysis, the characteristics of health state and global El score were included in the model. The predictive value of the model was significant $\left(R=0.470 ; R^{2}=0.221\right.$; correct. $R^{2}=0.151 ; F(6.67)=3.170$; $p<0.009)$. A special role was played by the percentage of body area changed, which in the set of qualities explained about $32 \%$ of the variability and independently about 25\% (partial correlation between the body area changed and SWL $=-0.251$ ). Furthermore, El explained in the set about $36 \%$ of SWL variability and independently about 38\% (partial correlation between El and SWL = 0.377) (Table 3). The smaller percentage of body area changed with psoriasis and the higher El, the greater satisfaction with life characterised the examined patients.

Subsequently, the model was checked with replacing the global El construct with individual factors as the previous analyses showed a significant role of factor I - using emotions in thinking and acting, and an extremely insig-

Table 3. Results of multiple regression analysis of a dependent variable - satisfaction with life in group of patients with psoriasis

\begin{tabular}{|c|c|c|c|c|c|c|}
\hline Independent variables & $b^{\star}$ & $\begin{array}{l}\text { Err. std. } \\
\text { from } b^{\star}\end{array}$ & $b$ & $\begin{array}{l}\text { Err. std. } \\
\text { from } b\end{array}$ & $t(67)$ & Value of $p$ \\
\hline R. free & & & 0.489 & 5.895 & 0.08 & 0.934 \\
\hline Time of illness [years] & 0.135 & 0.113 & 0.060 & 0.051 & 1.19 & 0.240 \\
\hline PASI - global result & 0.076 & 0.148 & 0.047 & 0.093 & 0.51 & 0.610 \\
\hline Occupied area of the body & -0.316 & 0.149 & -0.308 & 0.145 & -2.12 & 0.038 \\
\hline INTE Raw score & 0.360 & 0.108 & 0.158 & 0.048 & 3.33 & 0.001 \\
\hline Other diseases $(1=$ yes, $0=$ no $)$ & -0.017 & 0.110 & -0.318 & 2.003 & -0.16 & 0.874 \\
\hline Number of hospitalizations & 0.004 & 0.114 & 0.002 & 0.072 & 0.03 & 0.973 \\
\hline
\end{tabular}

$b^{*}$-standardized regression coefficient, Err. std. from $b^{*}-$ error standard from $b^{*}, b-$ regression coefficient, Err. std. from $b-$ error standard from $b$

Table 4. Results of multiple regression analysis of dependent variable - satisfaction with life in the group of patients with psoriasis

\begin{tabular}{|c|c|c|c|c|c|c|}
\hline Independent variables & $b^{\star}$ & $\begin{array}{l}\text { Err. std. } \\
\text { from } b^{\star}\end{array}$ & $b$ & $\begin{array}{l}\text { Err. std. } \\
\text { from } b\end{array}$ & $t(66)$ & Value of $p$ \\
\hline R. free & & & 4.074 & 5.333 & 0.76 & 0.448 \\
\hline Time of illness [years] & 0.166 & 0.115 & 0.074 & 0.051 & 1.43 & 0.156 \\
\hline PASI - Global result & 0.070 & 0.151 & 0.044 & 0.094 & 0.46 & 0.646 \\
\hline Occupied area of the body & -0.294 & 0.152 & -0.287 & 0.148 & -1.94 & 0.057 \\
\hline Other diseases $(1=$ yes, $0=$ no $)$ & -0.029 & 0.112 & -0.535 & 2.053 & -0.26 & 0.795 \\
\hline Number of hospitalizations & 0.015 & 0.116 & 0.009 & 0.073 & 0.13 & 0.899 \\
\hline $\begin{array}{l}\text { INTE factor I - the use of emotion in } \\
\text { thought and action }\end{array}$ & 0.329 & 0.111 & 0.662 & 0.224 & 2.95 & 0.004 \\
\hline $\begin{array}{l}\text { INTE factor II - emotion recognition } \\
\text { ability }\end{array}$ & 0.080 & 0.113 & 0.137 & 0.194 & 0.71 & 0.481 \\
\hline
\end{tabular}


nificant role of factor $1 \mathrm{I}$ - ability to recognise emotions. The predictive value of the whole model was slightly lower $\left(R=0.460 ; R^{2}=0.211 ;\right.$ correct. $R^{2}=0.128 ; F(7.66)=2.524$; $p<0.023)$. However, an important change concerned the characteristics of the clinical state - percentage of body area changed, the predictive value of which lost its statistical significance in spite of the fact that the percentage of variability explained was only slightly lowered (partial correlation between the body area changed and $S W L=-0.232$ ). A significant role was played only by factor I - using emotions in thinking and acting, which in the set of qualities explained 33\% of SWL variability and independently about 34\% (Table 4). The higher El expressed in using emotions in thinking and acting, the greater satisfaction with life in the examined group.

\section{Discussion}

The main aim of the research presented is to determine the relation between the personal resource, i.e. $\mathrm{E}$ and satisfaction with life in the group of people suffering from psoriasis. Firstly, the relation was assumed to be positive, that is, people with higher El would present a greater satisfaction with life. Attention was also paid to the role of health state characteristics, which turned out to modify the relation.

The results obtained allowed us to confirm the first assumption. The examined people with psoriasis presented a greater satisfaction with life when they had higher El, and in particular when they were able to use emotions in thinking and acting.

The result is similar to the ones obtained previously, even though they were obtained from a group of healthy people - students [44] and regardless of nationality (examination of the Canadians and the Scotch). The varying significance of isolated factors of El was confirmed as well. Emotional intelligence is not a homogenous construct. Its factor focusing on using emotions in thinking and acting plays a much more significant role than mere ability to recognise emotions $[29,45]$. It seems that El plays the role of a resource as much as it really helps an individual to function. It turns out that not only the access to one's own resources, but also their modifying influence on the consequences of stressful events is important for them to play their role $[31,46]$.

Such a role of $\mathrm{El}$ is especially noticeable in the group of women and the elderly with psoriasis. Such a relation was not observed in the group of men and younger people. In spite of the fact that as far as the relation between El and SWL taking age and sex into account is concerned, the results are ambiguous [18, 22], similar results were obtained for a group of people with Hashimoto's disease. Women were characterised by a greater satisfaction with life than men [47]. It is possible that the causes of such a situation should be looked for in individual differences. Moreover, the elderly as usually less active may be able to draw more from their resources. That issue requires further research and analysis.

The research into type 1 patients [47] showed that emotional control, which reflects the influence of the individual on the course and external expression, and the consequences of emotions, i.e. the ability to react in the way that is the most desired by the individual [48] helped to sustain satisfaction with life in spite of a severe somatic disease [20]. Therefore, the results obtained, which make it possible to treat EI as the predictor of SWL seem to be logical. The factor - using emotions in thinking and acting - is a particularly strong determinant of SWL. Consequently, satisfaction with life of people with psoriasis may be predicted basing on their El.

The second aim of the research was to check the significance of the health state of the examined patients for the relation between EI and SWL. In the opinion of the authors of the method presented in this research El is correlated with a better health state [42], however, to a greater degree with psychical than physical health as it is suggested by applied meta-analyses [49]. Health, according to Hobfoll [46], is one of important resources of a state that facilitate acquiring other kinds of resources. The results obtained allow us to formulate the following conclusions:

l) people ill for a longer period of time are characterised by higher El, but only in the group that was ill for a shorter time, a statistically significant relation between SWL and EI and its factor I - using emotions in thinking and acting was found.

For example, in the group of patients with GravesBasedow disease, the length of the disease started the spiral of losses contributing to the increase in such phenomena as the level of neuroticism, emotional motivation and avoidance strategy of dealing with stress [47]. The result obtained in the group of patients with psoriasis suggests an opposite process, i.e. despite prolonged health loss, the patients were able to use their own resources.

However, the relation between the length of disease and the correlation between one's own resources and satisfaction with life was present only in the group that was ill for a shorter time. The role of resources for SWL is significant only in the group that is at the stage of accustoming themselves to the disease and when they get accustomed, the resources do not play such an important role any more.

II) psoriasis severity measured with PASI and the percentage of body area changed by the disease do not differentiate the degree of El and SWL in the research group.

As regards that issue, ambiguity may be observed in the results obtained so far. Satisfaction with life may be treated as a manifestation of psychological adaptation [50], but not all chronically ill are able to adapt to the life with a chronic disease. When the health deteriorates, a fall in satisfaction with life may occur. It should be remembered, however, that the chronically ill find satisfac- 
tion in life in different areas from the healthy ones and, therefore, a severe course of disease does not always mean a decrease in SWL [25].

III) taking the severity of psoriasis and the percentage of the body area changed into account, there are statistically significant relations between $\mathrm{El}$ and its factors and SWL; in the case of greater psoriasis severity, El as a whole plays a significant role. However, in the situation of smaller severity, only factor I - using emotions in thinking and acting - significantly correlates with SWL If the percentage of the body area changed is taken into account, both the whole construct and the two factors independently reveal a significant relation to satisfaction with life. With a smaller body area changed, neither El nor any of its factors independently reveal a statistically significant relation to SWL.

The next conclusion drawn from the research presented shows that some of the disease qualities may be more strongly correlated with the relation between resources and one's own life evaluation. The more severe psoriasis was and the larger body area was changed (as a result, also uncovered body parts had to be changed), the more clearly El helped to evaluate one's life as satisfying. In such a situation, its role as a resource helping to deal with a difficult situation and buffering against the negative consequences of the disease is easily observable.

\section{Conclusions}

To sum up, it may be stated that El as a resource makes it possible to predict the increase in satisfaction with life in the group of people with psoriasis. In addition, some health state characteristics, and the percentage of body area changed by the disease in particular, fulfil a similar, although slightly weaker, role. The more effectively people are able to use emotions in thinking and acting when the disease did not change too large body area, the more satisfaction they are able to draw from life. Although El overlaps personality to a large degree, independently it also explains the variability of satisfaction with life [51].

It should, however, be remembered that El is not always able to help individuals to function, that its role is limited. It did not help to alleviate the relation between everyday troubles and tension [52] and it is not the determinant of adapting to the disease in every group of people [53].

\section{References}

1. Łuczkowska M, Żaba R. Psoriasis. Przegl Lek 2005; 7: 38-49.

2. Tarajkowska-Olejnik A. Psoriasis. Health Service, 2000, 5356, Download 20.03.2010, http://www.sluzbazdrowia.com. pl/artykul.php?numer_wydania $=2946 \&$ art $=1$

3. Placek W, Protas-Drozd, F. Psoriasis (Psoriasis vulgaris). Download 15.04.2010 http://luszczyca.org.pl/p1/?luszczyca-(psoriasis-vulgaris), 80
4. Janowski K. Personality determinants of coping in psoriasis. Polihymnia Press, Lublin 2006.

5. Rasmy H, Mikhael N, Ismail S. Interleukin-18 expression and the response to treatment in patients with psoriasis. Arch Med Sci 2011; 7: 713-9.

6. Mazzetti M, Mozzetta A, Soavi GC, et al. Psoriasis, stress and psychiatry: psychodynamic characteristics of stressors. Acta Derm Venereol Suppl 1994; 186: 62-4.

7. Steuden S, Janowski K. Psychodermatological diseases. Przegl Dermatol 2002; 89: 175-83.

8. Bojar I, Humeniuk E, Owoc A, et al. Exposing women to workplace stress factors as a risk factor for developing arterial hypertension. Ann Agric Environ Med 2011; 18: 175-82.

9. Al'Abadie MS, Kent GG, Gawkrodger DJ. The relationship between stress and the onset and exacerbation of psoriasis and other skin conditions. Br J Dermatol 1994; 130: 199-203.

10. Griffiths CE. Richards HL. Psychological influences in psoriasis. Clin Exp Dermatol 2001; 26: 338-42.

11. Barankin B, DeKoven J. Psychosocial effect of common skin diseases. Can Fam Physician 2002; 48: 712-6.

12. Polańska A, Dańczak-Pazdrowska A, Silny W, et al. High-frequency ultrasonography in monitoring the effects of treatment of selected dermatoses. Postep Derm Alergol 2011; 28: 255-60.

13. Willemsen R, Roseeuw D, Vanderlinden J. Alexithymia and dermatology: the state of the art. Int I Dermatol 2008; 47: 903-10.

14. Masmoudi J, Maalej I, Masmoudi A, et al. Alexithymia and psoriasis: a case-control study of 53 patients. Encephale 2009; 35: 10-1.

15. Ogłodek E, Araszkiewicz A, Placek W. Stigmatization of people with psoriasis. Public Health 2009; 119: 335-7.

16. Hrehorów E, Reich A, Szepietowski J. Quality of life in patients with psoriasis: dependence itching, stress and depressive symptoms. Clin Dermatol 2007; 9: 19-23.

17. Miękoś-Zydek B, Ryglewska-Cho A, Lassota-Falczewska M, et al. Quality of life in patients with psoriasis. Postep Derm Alergol 2006; 23: 273-7.

18. Pavot W, Diener E. Review of the satisfaction with life scale. Psychological Assessment 1993; 5: 164-72.

19. Diener E, Oishi S, Lucas RE. Personality, culture, and subjective wellbeing: emotional and cognitive evaluations of life. Annu Rev Psychol 2003; 54: 403-25.

20. Pilcher JJ. Affective and daily event predictors of life satisfaction in college students. Social Indicators Research 1998; 43: 291-306.

21. Schimmack U, Radhakrishnan P, Oishi S, et al. Culture, personality, and subjective well-being: integration process models of life satisfaction. J Pers Soc Psychol 2002; 82: 58293.

22. Ogińska-Bulik N, Juczyński Z. Personality determinants of life satisfaction. In: Psychology of health - looking for positive inspiration. Heszen J, Życińska J (eds.). ACADEMICA SWPS Press, Warsaw 1998; 89-102.

23. Huovinen E, Kaprio J, Koskenvuo M. Asthma in relation to personality traits, life satisfaction and stress: a prospective study among 11.000 adults. Allergy 2001; 56: 971-7.

24. Juczyński Z. Measurement tool in health promotion and psychology. Psychological Testing Laboratory PTP, Warsaw 2001.

25. Basińska MA, Marzec A. Satisfaction of life in patients with chronic diseases. Annales Academiae Medicae Silesiensis 2007; 61: 1-7.

26. Łuczak-Wawrzyniak J, Szczepańska M, Skrzypczak J. Quality of life in women diagnosed with endometriosis and meth- 
ods of dealing with the negative effects of the disease. Prz Menopauzalny 2007; 11: 329-35.

27. Sęk H. Introduction to clinical psychology. Scholar Press, Warsaw 2001

28. Heszen I, Sęk H. Psychology of health. PWN Press, Warsaw 2007.

29. Basińska MA, Woźniewicz A. Emotional intelligence as a determinant of illness acceptance in patients with psoriasis. Przegl Dermatol 2012; 99: 202-9.

30. Poprawa R. Personal resources to cope with stress. In: Basics of health psychology. Dolińska-Zygmunt G (ed.). University in Wrocław Press, Wrocław 2001; 143-55.

31. Mudyń K. Do we have the resources do not have access to them? Problem of resource availability. In: Personal and social resources conducive to the health of the individual. Juczyński Z, Ogińska-Bulik N (eds.). University in Łódź Press, Łódź 2003; 63-77.

32. and the types of behavior and experience of working in a group of professional soldiers. Polish Psychological Forum 2007; 12: 80-92.

33. Andruszkiewicz A, Basińska MA. Emotional Intelligence in nurses and types of behavior and experience in working. In: Health - stress - disease in psychological dimension. Wrona-Polańska H (ed.). Impuls Press, Kraków 2008; 75-85.

34. Jaworowska A, Matczak A. Emotional Intelligence Questionnaire. Psychological Testing Laboratory of the Polish Psychological Association. Warsaw, 2001.

35. Mayer JD, Salovey P. What is emotional intelligence? In: Emotional development and emotional intelligence. Salovey P, Sluyter DJ (eds.). Rebis Press, Poznań 1999; 21-70.

36. Piekarska A. Emotional intelligence of young people and the ways parents respond in problem situations. Developmental Psychology 2004; 9: 23-33.

37. Matczak $A$. The role of temperament in human development. Developmental Psychology 2004; 9: 9-21.

38. Goleman D. Emotional intelligence. Media Family Press, Poznań 1997.

39. Bar-On R, Brown JM, Kirkcaldy BD, Thome EP. Emotional expression and implications for occupational stress: an application of the emotional quotient inventory (EQ-i). Pers Individ Dif 2000; 28: 1107-18.

40. Ciarrochi J, Scott G. The link between emotional competence and well-being: a longitudinal study. Br J Guidance Counsel 2006; 34: 231-43.

41. Mikolajczak M, Petrides KV, Hurry J. Adolescents choosing self-harm as an emotion regulation strategy: the protective role of trait emotional intelligence. Br J Clin Psychol 2009; 48: 181-93.

42. Schutte NS, Malouff JM, Thorsteinsson EB, et al. A meta-analytic investigation of the relationship between emotional intelligence and Heath. Pers Individ Dif 2007; 42: 921-33.

43. Gross JJ, John OP. Individual differences in two emotion regulation processes: implications for affect, relationships, and well-being. J Pers Soc Psychol 2003; 85: 348-62.

44. Bastian VA, Burns NR, Nettelbeck T. Emotional intelligence predicts life skills, but not as well as personality and cognitive abilities. Personality and Individual Differences 2005; 39: 1135-45.

45. Palmer B, Donaldson C, Stough C. Emotional intelligence and life satisfaction. Pers Individ Dif 2002; 33: 1091-100.

46. Hobfoll SE. Stress, culture and society. Psychology and philosophy of stress. Psychological Press in Gdańsk, Gdańsk 2006.
47. Basińska MA. Mental functioning of patients in selected endocrine diseases. Somatic and personality conditions. Kazimierz Wielki University Press, Bydgoszcz 2009.

48. Strelau J. Personality as a set of features. In: Psychology. Academic handbook. Strelau J (ed.). Psychological Press in Gdańsk, Gdańsk 2000; 525-60.

49. Martins A, Ramalho N, Morin E. A comprehensive meta-analysis of the relationship between Emotional Intelligence and health. Pers Individ Dif 2010; 49: 554-64.

50. Chang EC, Sanna LJ. Optimism, pessimism, and positive and negative affectivity in middle-aged adults: a test of a cognitive-affective model of psychological adjustment. Psychol Aging 2001; 16: 524-31.

51. Gannon N, Ranzijn R. Does emotional intelligence predict unique variance in life satisfaction beyond IQ and personality? Personality and Individual Differences 2005; 38: 1353-64.

52. Day AL, Therrien DL, Carroll SA. Predicting psychological health: assessing the incremental validity of emotional intelligence beyond personality, type A behaviour, and daily hassles. Eur J Pers 2005; 19: 519-36.

53. Willard S. Relationship of emotional intelligence and adherence to combination antiretroviral medications by individuals living with HIV disease. JANAC 2006; 17: 16-26. 